\title{
Self-Optical Coherence Tomography and Angiography
}

\author{
Ahmad M. Mansour \\ Department of Ophthalmology, American University of Beirut, Beirut, Lebanon; \\ Department of Ophthalmology, Rafic Hariri University Hospital, Beirut, Lebanon
}

\section{Keywords}

Auto-ophthalmoscopy · Macula - Optical coherence tomography - Optical coherence tomography angiography $\cdot$ Self-examination

\begin{abstract}
Purpose: To present a new concept of self-optical coherence tomography (OCT) and selfOCT angiography. Methods: The operator sits in the patient seat and manipulates the instrument body via the joystick with the dominant hand, while the dominant index is ready to press the capture button and while focusing on the fixation target. One senior ophthalmologist judged various OCT machines for ease of self-scan during a major ophthalmic convention. Separately, self-scans were also captured using a single OCT machine by one senior ophthalmologist and 5 junior optometrists and the scans were analyzed for both centration and image quality value (IQV), and compared to regular scans done by an operator. Results: Ten available OCT machines were tested for their ability to allow self-OCT. Machines that had one or more features of auto-alignment, auto-focus, and auto-shoot were ideal for self-OCT or self-OCT angiography. Self-scans done by the ophthalmologist (total 27 scans of right eye, mean IQV $=32.6$, and 24 left eyes, mean IQV $=37.3$, done over 9 months) and 5 optometrists (total 24 scans, mean 34.8 done in one session) were comparable to scans (total 11 ,
\end{abstract}


mean IQV = 38.1) done by an operator for image quality. Decentration was very common in self-scans of the macula ( $37 \%$ right eye and $46 \%$ left eye) versus $0 \%$ for scans of the right eye done by an operator. Conclusions: Self-OCT scans of the macular region can be done with good image quality but are often decentered. Advantages include privacy, potential use by ophthalmic health professionals, airspace station officers, and possible future home selfimaging of macula.

\section{Introduction}

Since Helmholtz's invention more than 150 years ago, ophthalmoscopy devices have evolved as direct and indirect ophthalmoscope. Most recently, optical coherence tomography (OCT) has enhanced detailed retinal imaging in a quick noninvasive nonmydriatic manner. Frequent retinal exams and early detection of disease are two of the best ways to monitor macular diseases. If an exam is made easy enough to do frequently by oneself in the convenience and privacy of one's own time, then ophthalmologists and other ophthalmic care deliverers can benefit from this self-retina test. Ophthalmologists worldwide have exceeded 200,000 [1] in number (and likewise for optometrists) and many suffer from retinal pathology [1]. Physicians globally, including ophthalmologists, have a lower mortality risk from cancer and heart disease relative to the general population, presumably related to early diagnosis and self-care [2]. In the UK, a majority of physicians (63\%) revert to self-diagnosis and treatment [3]. In Canada, the mean age of all physicians has been steadily increasing over time with ophthalmologists being, on average, 2.3 years older than other physicians [4]. Also in 2011, the mean age of all Canadian ophthalmologists was 53.1 years [4]. With the eye care health delivery personnel getting older and bigger [4], self-test of the macula would be an attractive proposition worldwide. Hence we described self-OCT (with or without angiography) as a convenient retinal test for ophthalmologists, optometrists, or retina photographers who need macular monitoring, after approval by Institutional Review Board.

\section{Technique}

Ten available OCT machines were tested by one operator under room light for their ability to allow self-OCT with the assistance of senior product manager, director of clinical application, or optical engineer involved in technology development of these companies during a major international ophthalmology tradeshow. The operator (A.M.M.) was not familiar with any OCT machine prior to that test. Self-OCT appears as a viable option in all machines and is easy to perform with variable degrees of success depending on the familiarity with the machine, but mostly the automatic features of the machine and the need to press several functions on a screen or the use of joystick button.

Subsequently we concentrated on one machine to analyze the difference between operators and to compare the results with regular scans. Using 3D OCT-2000 FA plus (Topcon Medical Systems, Tokyo, Japan), we press the 3D Macula $6.0 \times 6.0 \mathrm{~mm}$ (resolution $512 \times 128$ ) scan pattern display button with OCT autofocus function ON, IR filter selector pushed in, 


\section{Case Reports in Ophthalmology}

Case Rep Ophthalmol 2017;8:108-115

(C) 2017 The Author(s). Published by S. Karger AG, Base www.karger.com/cop

Mansour: Self-Optical Coherence Tomography and Angiography

illumination level set at 1 (minimum), internal fixation target position selector button set for $\mathrm{M}$ (macula), and internal fixation target shape selector button set for cross. Under dim light and while looking at the fixation target, the instrument body is moved with the control lever kept upright using the right hand and intermittently pressing with the index the button to get the scans. When it is in excellent focus, the machine automatically scans the fovea and the flash appears for the macular photograph (Fig. 1). One operator (A.M.M.) repeated self-scans over a 1-year period to both eyes. These self-scans were compared to scans of the right eye of the same operator (A.M.M.) and to self-scans done by 5 optometrists (all familiar with the machine) to the right eye in a single setting. Variables analyzed included decentration (either vertical or horizontal) and image quality value (IQV): IQV is machine generated and does not relate to decentration; values of 45 or above reflect good quality scan.

\section{Results}

The 10 machines were tested by one operator and were listed by decreasing order of facility for self-OCT: (1) Topcon 3D OCT-1 Maestro (Topcon Medical Systems) (autoalignment, auto-focus, and auto-shoot is activated on touching the capture icon on the screen); (2) Nidek Retina Scan Duo (Nidek, Aishi, Japan) (3D auto-tracking and auto-shot; operator does alignment); (3) Optovue Avanti RTVue XR (using auto-adjust option allows adjustment of height and refraction with $3 \mathrm{~mm}$ scanning window depth) (Optovue, Fremont, CA, USA) (Fig. 2, Fig. 3); (4) RTVue-100 Fourier-domain OCT (Optovue); (5) Topcon DRI OCT (Topcon Medical Systems); (6) Topcon 3D 2000 FA plus (Topcon Medical Systems); (7) Heidelberg Engineering Spectralis (Heidelberg Engineering, Heidelberg, Germany); (8) Canon OCT-HS 100 (Canon, Amstelveen, The Netherlands); (9) Carl Zeiss Meditec AngioPlex OCT angiography (Carl Zeiss Meditec, Dublin, CA, USA); and (10) Carl Meditec Zeiss Cirrus HD OCT 500 (Carl Zeiss Meditec). In general, machines that use a joystick were by far much easier to use for self-scans than machines relying on a computer mouse.

The performance results for one machine use by 5 optometrists and by a senior ophthalmologist are listed in Table 1. The ophthalmologist had macular disease, dry eye, and miotic pupil bilaterally. The optometrists were young with wide pupils and normal tear film. Decentration was present in an average of $12 \%$ (range $0-20 \%$ ) of right eye scans done by optometrists. Decentration of the scan was 37\% for right (dominant) eye scans and $46 \%$ for left eye scans of the ophthalmologist. There was no decentration noted in the scans done on the ophthalmologist by an operator. Mean ( \pm standard deviation) IQV was $34.8( \pm 10.5)$ for the combined optometrist group self-scan of the right eye, $32.6( \pm 9.8)$ for the right eye of the ophthalmologist self-scans, $37.3( \pm 7.5)$ for the left eye of the ophthalmologist self-scans, and $38.1( \pm 7.7)$ for the right eye scans of the ophthalmologist performed by an operator.

Self-monitoring of macular disease ad lib allowed great psychologic relief to the senior ophthalmologist: unlimited access to the OCT machine, freedom from seeking colleague help, and protection of confidentiality and privacy. 


\section{Case Reports in Ophthalmology}

Case Rep Ophthalmol 2017;8:108-115

(c) 2017 The Author(s). Published by S. Karger AG, Base www.karger.com/cop

Mansour: Self-Optical Coherence Tomography and Angiography

\section{Discussion}

It has been recognized that when physicians are patients, they experience unique challenges in accessing care, such as fear of disability, inability to reverse roles, and fear of loss of confidentiality and privacy. Advances in technology have made it possible to self-test for a variety of medical conditions. Medical test kits for home use can help in diagnosis (home pregnancy test), monitoring (glucose test), or screening (cholesterol or triglyceride level). A self-exam is advocated in subjects at high risk for diseases such as skin melanoma, breast cancer [5], thyroid, or testes.

Auto-ophthalmoscopy has a long history dating back to 1863 [6-9]. Several techniques have been described for visualizing one's own retina: Heymann (1863), Eber (1922), Vianna (1935), Leydhecker (1936), Drews (1942), Cohen (1966) [6], Bullock (1967) [7], Craggs (1983) [8], and Armor and Kirby (2005) [9]. The reasons for this search have varied from increasing skills of the use of the ophthalmoscope, academic achievement, professional independence, and self-monitoring of ocular disease. The different techniques for autoophthalmoscopy have used an ophthalmoscope and mirror(s), convex lens, prism, or blackened tube. All these methods required a learning curve, were time-consuming and with low yield due to limitation of the direct ophthalmoscopy (small field of view and absence of photographic documentation).

In the same way, self-OCT can be performed by ophthalmologists (or optometrists or ophthalmic photographers) at their own will, free time, and when they have any complaint without disclosing their diagnosis to others. Convenience, simplicity, time efficiency, and discretion would help propagate this self-test all over the ophthalmology community. Besides, self-OCT may foster research such as diurnal $[10,11]$ OCT changes and OCT changes in the International Space Station [12]. Mader et al. [13] have been doing self-assessment of the optic disc in astronauts for several years. Moreover, using the same technique, self-OCT angiography can be easily performed (Fig. 2). Self-OCT relies on scanning a wide area in the macular region and hence has several limitations from inability to scan a localized area outside the macula. We did not attempt yet optic disc evaluation as described by Mader et al. [13]. Also elderly subjects with small pupil, dry eyes, and early cataract appear to get more decentered scans than younger subjects. Self-OCT performance is machine dependent, being very simple in machines possessing self-capture or automatic capture features. Familiarity with the machine plays an additional role in getting better image quality.

\section{Statement of Ethics}

The present research complies with the guidelines for human studies. Subjects have given their informed consent and the study protocol was approved by the institute's committee on human research. 


\section{Case Reports in Ophthalmology}

Case Rep Ophthalmol 2017;8:108-115

(C) 2017 The Author(s). Published by S. Karger AG, Basel www.karger.com/cop

Mansour: Self-Optical Coherence Tomography and Angiography

\section{Disclosure Statement}

The author has no financial interest in any product mentioned and the study received no financial support.

\section{References}

Resnikoff S, Felch W, Gauthier TM, Spivey B: The number of ophthalmologists in practice and training worldwide: a growing gap despite more than 200,000 practitioners. $\mathrm{Br} J$ Ophthalmol 2012;96:783-787. Stavem K, Hofoss D, Aasland OG, Loge JH: The self-perceived health status of Norwegian physicians compared with a reference population and foreign physicians. Scand J Public Health 2001;29:194-199. Steffen MW, Hagen PT, Benkhadra K, Molella RG, Newcomb RD, Murad MH: A survey of physicians' perceptions of their health care needs. Occup Med (Lond) 2015;65:49-53.

4 Buys YM: Aging and feminization of the physician workforce in Canada: comparing ophthalmologists to all other physicians. Can J Ophthalmol 2014;49:291-296. Jacob TC, Penn NE, Brown M: Breast self-examination: knowledge, attitudes, and performance among black women. J Natl Med Assoc 1989;81:769-776. Cohen SW: Self-ophthalmoscopy. Am J Ophthalmol 1966;61:343-345. Bullock JD: Auto-ophthalmoscopy. Arch Ophthalmol 1967;78:422-423. Craggs J: Simple method for auto-ophthalmoscopy. Brit J Ophthalmol 1983;67:330-331. Armor RH, Kirby MG: Auto-ophthalmoscopy: a novel way to practice retinal examination. Brit J Diabetes Vasc Dis 2005;5:142-144.

10 Polito A, Del Borrello M, Polini G, Furlan F, Isola M, Bandello F: Diurnal variation in clinically significant diabetic macular edema measured by the Stratus OCT. Retina 2006;26:14-20.

11 Gupta B, Grewal J, Adewoyin T, Pelosini L, Williamson TH: Diurnal variation of macular oedema in CRVO: prospective study. Graefes Arch Clin Exp Ophthalmol 2009;247:593-596.

12 Mader TH, Gibson CR, Pass AF, Kramer LA, Lee AG, Fogarty J, et al: Optic disc edema, globe flattening, choroidal folds, and hyperopic shifts observed in astronauts after long-duration space flight. Ophthalmology 2011;118:2058-2069.

13 Mader TH, Gibson CR, Otto CA, Sargsyan AE, Miller NR, Subramanian PS, et al: Long-duration space flight: implications for pathogenesis. J Neuroophthalmol 2016, Epub ahead of print. 


\section{Case Reports in Ophthalmology}

Case Rep Ophthalmol 2017;8:108-115

(C) 2017 The Author(s). Published by S. Karger AG, Basel www.karger.com/cop

Mansour: Self-Optical Coherence Tomography and Angiography
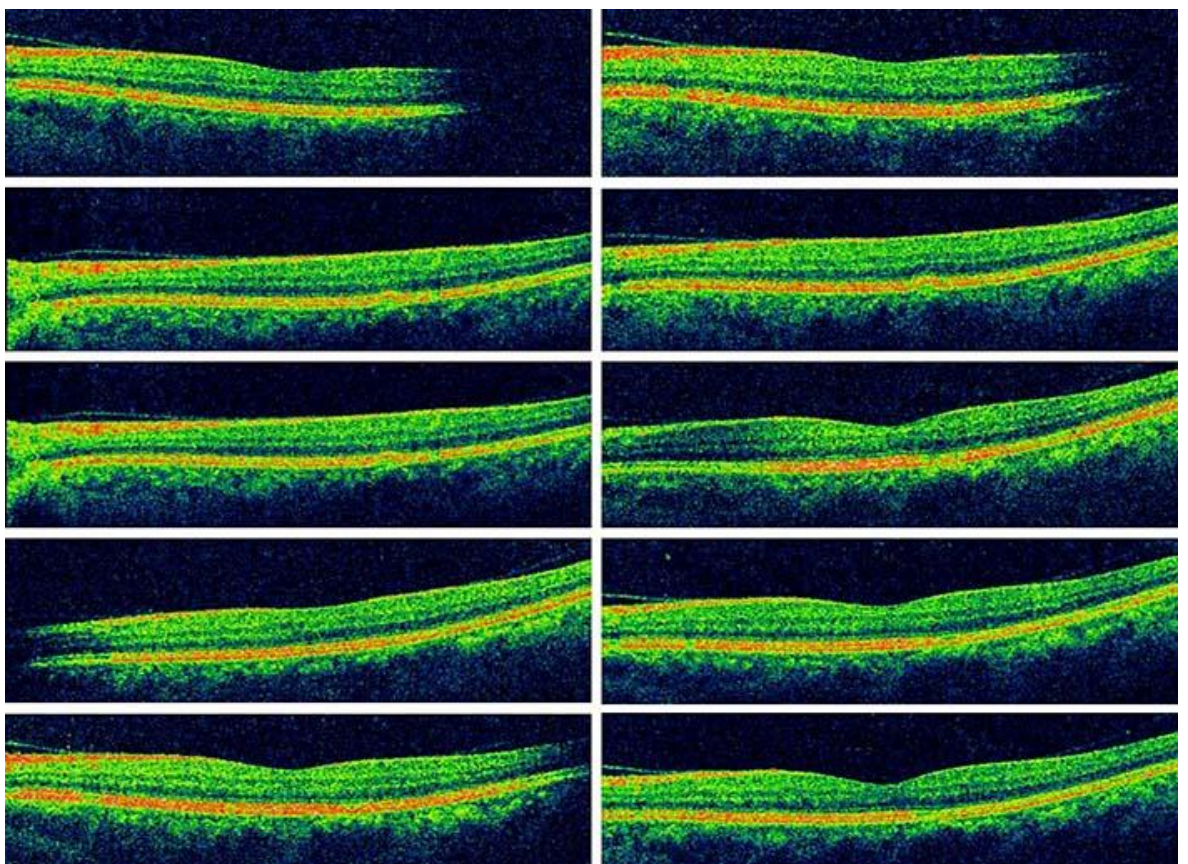

Fig. 1. Ten sequential consecutive unedited central self-OCT scans of the left macula (Topcon 3D $2000 \mathrm{FA}$ plus set for $6.0 \times 6.0 \mathrm{~mm}$ 3D Macula scan pattern). 


\section{Case Reports in Ophthalmology}

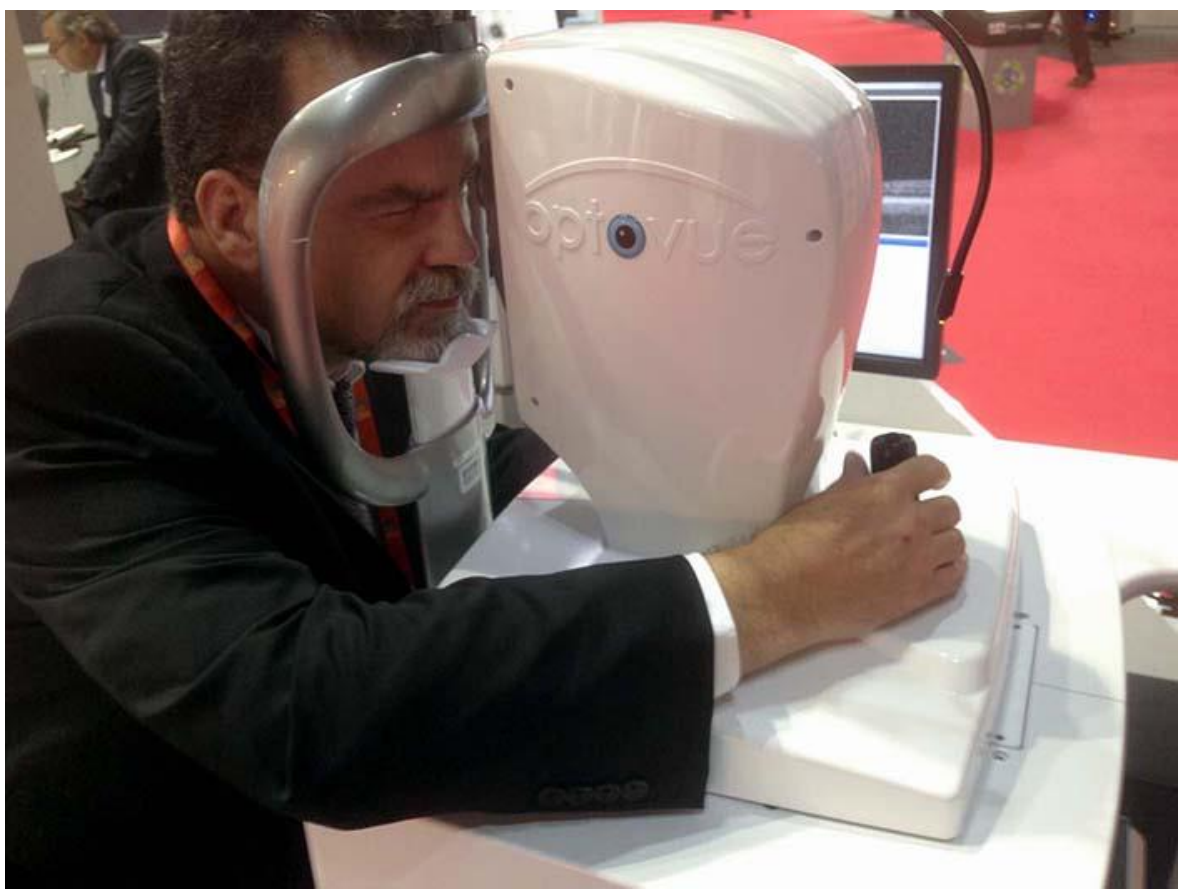

Fig. 2. Operator position during self-OCT angiography (Optovue Avanti RTVue XR). While looking at the fixation target, the instrument body is moved with the control lever using the right hand.

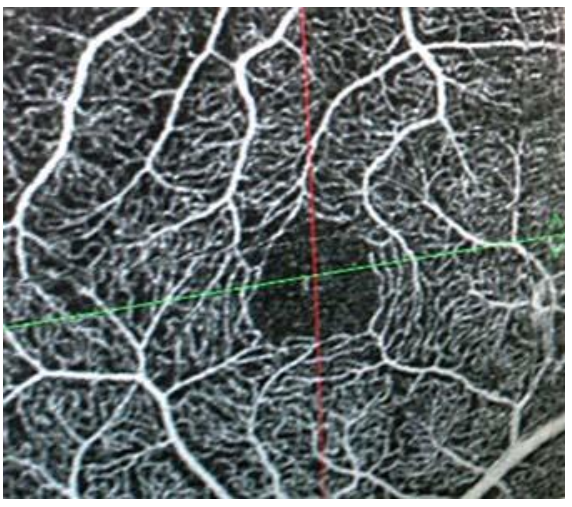

Fig. 3. Self-OCT angiography captured with Optovue Avanti RTVue XR. 
Table 1. Clinical characteristics of operators using Topcon 3D 2000 FA plus OCT set for $6.0 \times 6.0 \mathrm{~mm}$ 3D Macula scan pattern

\begin{tabular}{|c|c|c|c|c|c|c|c|c|c|}
\hline & $\begin{array}{l}\text { Self-OCT right } \\
\text { eye of No. } 1 \\
\text { optometrist }\end{array}$ & $\begin{array}{l}\text { Self-OCT right } \\
\text { eye of No. } 2 \\
\text { optometrist }\end{array}$ & $\begin{array}{l}\text { Self-OCT right } \\
\text { eye of No. } 3 \\
\text { optometrist }\end{array}$ & $\begin{array}{l}\text { Self-OCT right } \\
\text { eye of No. } 4 \\
\text { optometrist }\end{array}$ & $\begin{array}{l}\text { Self OCT-right } \\
\text { eye of No. } 5 \\
\text { optometrist }\end{array}$ & $\begin{array}{l}\text { Self-OCT right } \\
\text { eye combining } \\
5 \text { optometrists }\end{array}$ & $\begin{array}{l}\text { Self-OCT right } \\
\text { eye of senior } \\
\text { ophthalmologist }\end{array}$ & $\begin{array}{l}\text { Self-OCT left } \\
\text { eye of senior } \\
\text { ophthalmologist }\end{array}$ & $\begin{array}{l}\text { OCT right eye done on } \\
\text { senior ophthalmologist } \\
\text { by an operator }\end{array}$ \\
\hline Age, years & 29 & 30 & 36 & 28 & 31 & 30.8 & 61 & 61 & 61 \\
\hline Gender & male & male & male & male & female & $\begin{array}{l}4 \text { male, } \\
1 \text { female }\end{array}$ & male & male & male \\
\hline \multicolumn{10}{|l|}{$\mathrm{IQV}$, mean } \\
\hline$(\mathrm{SD})$ & $45.6(7.2)$ & $38.7(4.4)$ & $30.5(15.3)$ & $27.8(1.8)$ & $28.5(11.1)$ & $34.8(10.5)$ & $32.6(9.8)$ & $37.3(7.5)$ & $38.1(7.7)$ \\
\hline \multicolumn{10}{|l|}{$\%$ OCT } \\
\hline centered & 80 & 83 & 100 & 80 & 100 & 88 & 63 & 54 & 100 \\
\hline
\end{tabular}

IQV, image quality value set by the machine; SD, standard deviation. 